\title{
Repositorios digitales y redes sociales académicas: ¿una coexistencia necesaria?
}

Javier Gómez-Castaño | Unidad de Apoyo a la Investigación, Biblioteca General, Universidad de Alicante

URL de la contribución <www.iaph.es/revistaph/index.php/revistaph/article/view/4628>

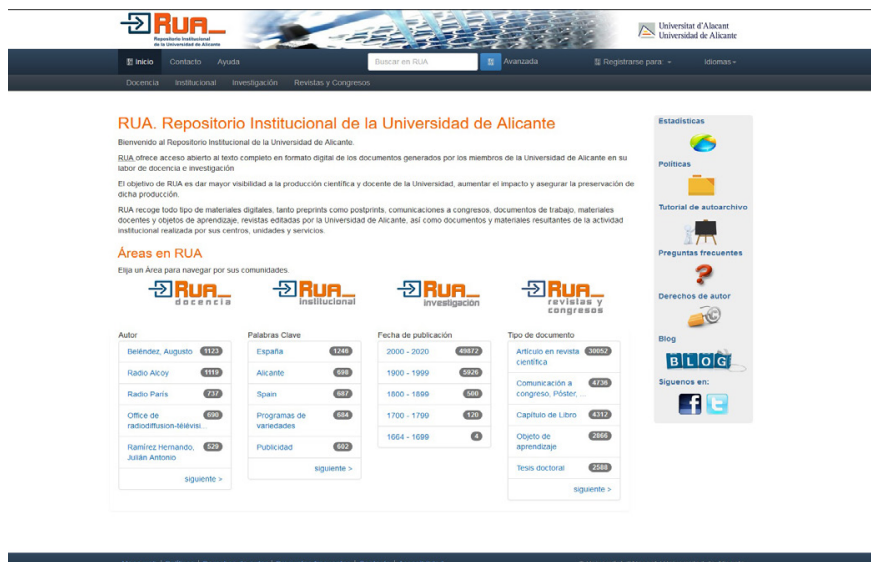

RUA, Repositorio Institucional de la Universidad de Alicante

Desde que surgieron los primeros repositorios institucionales universitarios a mediados de los años 2000, éstos han intentado evolucionar, con mayor o menor éxito, para ofrecer a los investigadores de sus respectivas instituciones una plataforma atractiva, sencilla y dinámica que les permitiera aunar en un único lugar toda su producción científica, dotando de herramientas de valor añadido a estos servicios web con el objetivo de "enganchar" a sus usuarios y fidelizarlos en el acto del autoarchivo de sus trabajos científicos. La pregunta que nos hacemos es: ¿lo han conseguido? La respuesta que puedo ofrecer, tras mi experiencia desde 2006 como coordinador de RUA, Repositorio Institucional de la Universidad de Alicante, es bastante simple: en algunos casos sí y en otros no.

¿Por qué algunos investigadores autoarchivan sus trabajos en RUA antes incluso de ser publicados en la revista que ha aceptado el trabajo? ¿Por qué hay investigadores que han depositado en el repositorio casi la totalidad de su producción científica, incluyendo materiales tan diversos como vídeos, datos de investigación, posters, etc.? Y, sin embargo, ¿por qué hay otros investigadores que no conocen la existencia de RUA, después de 14 años desde su puesta en marcha, o prefieren depositar sus trabajos en redes sociales académicas?

Estas preguntas nos obligan a plantearnos si nuestra política respecto al depósito de los trabajos de investigación en nuestros repositorios es la adecuada. Los responsables de los repositorios, y las instituciones en general, intentamos implementar medidas para incentivar el autoarchivo, como por ejemplo mandatos y recomendaciones, incentivos económicos, mejoras tecnológicas, etc. Aun así, el resultado obtenido con estas medidas no es del todo satisfactorio. El depósito de materiales en los repositorios se viene haciendo habitualmente por parte de los responsables de los mismos mediante el llamado "archivo delegado", quedando los propios autores de los trabajos al margen del acto del depósito.

El hecho de que nuestros investigadores no valoren de igual forma el que sus trabajos se encuentren aloja-

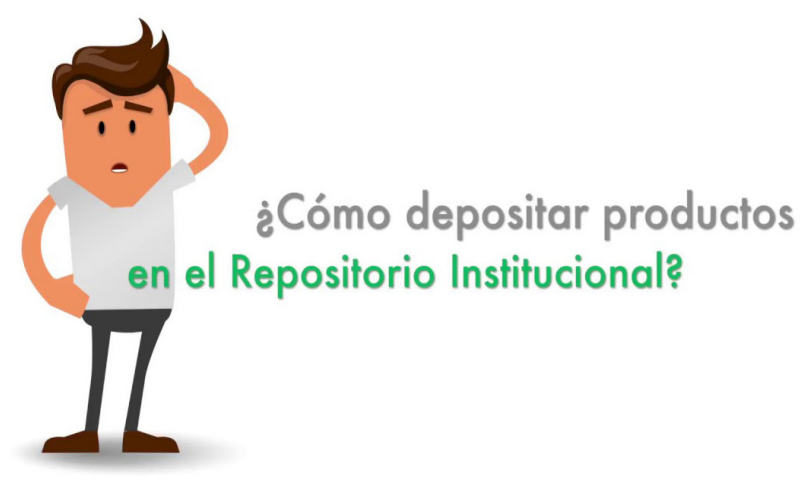

Vídeo tutorial sobre el proceso de depósito de producción en el Repositorio Institucional (RI), de la Universidad Autónoma del Estado de México 
a debate Repositorios y redes sociales académicas para la transferencia del conocimiento abierto

| coordina Remedios Melero Melero

dos en el repositorio de su propia institución, y prefieran difundirlos a través de redes sociales académicas como ResearchGate o Academia.edu puede deberse a distintas razones:

> Consideran que el depósito en un repositorio es más "farragoso" (más campos que rellenar, más controles por parte de los administradores, petición de versiones previas al PDF definitivo que puedan ponerse en abierto, etc.).

> Los servicios de valor añadido que ofrecen los repositorios no les aportan valor añadido real (las redes sociales, sin embargo, les dan datos de citas casi en tiempo real, quién se ha descargado el trabajo y desde dónde, sugerencias de trabajos similares, etc.).

> Piensan que los trabajos subidos a un repositorio no tienen la misma visibilidad que aquellos que se encuentran en una red social académica.

> Y por último, y quizás lo más habitual, subir sus trabajos al repositorio institucional supone un esfuerzo en forma de "tiempo perdido" en sus labores docentes, investigadoras o administrativas.

Para intentar combatir estas reticencias los repositorios institucionales están implementando desarrollos tecnológicos y operativos, con los a veces escasos recursos humanos y económicos de que disponen, que les hagan parecer más atractivos y funcionales.

En el caso del repositorio institucional de la Universidad de Alicante uno de nuestros objetivos principales es hacer la vida más fácil al investigador-autor a la hora del depósito de materiales. Para ello hemos habilitado una plataforma que permite archivar sus trabajos en el repositorio desde el currículum del investigador que deben rellenar en el campus virtual, simplemente adjuntando el archivo y rellenando unos pocos campos básicos. En cuanto a los servicios de valor añadido, los autores cuentan con estadísticas de visitas y descargas, altmétricas a nivel de ítem, difusión de los nuevos depósitos

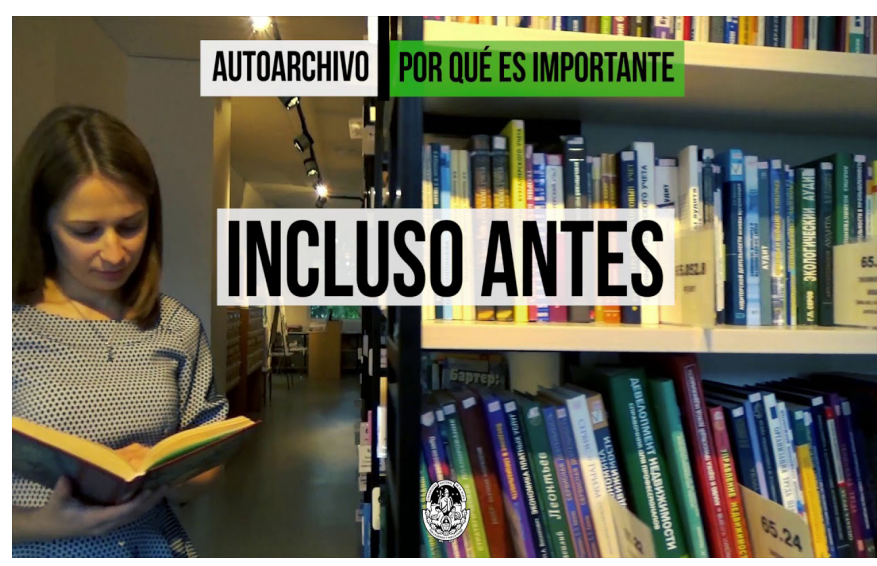

Autoarchivo. Vídeo tutorial del repositorio institucional de la Universidad Nacional de La Plata

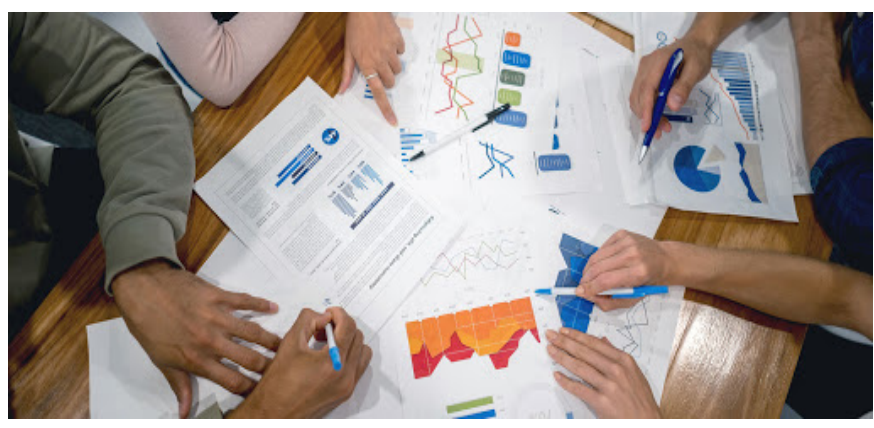

La visibilidad es un factor importante en la decisión de los investigadores a la hora de elegir por qué medio difunden sus trabajos | fuente Unidad de Información e Investigación Social y Sanitaria (UISYS) de la Universitat de València

en redes sociales generales como Twitter y Facebook, páginas personalizadas para los grupos de investigación, etc.

¿Todas estas medidas han ayudado a incentivar el autoarchivo y conseguir que el repositorio sea reconocido por el personal investigador como la principal vía para dar mayor difusión y visibilidad a sus publicaciones? No puedo sino contestar como al principio de este escrito: en algunos casos sí y en otros no.

En octubre de 2013 el Vicerrectorado de Investigación de la Universidad de Alicante enviaba un correo electrónico a los directores de departamentos e institutos universitarios indicándoles lo siguiente: "con el objetivo de 
cumplir con este requisito [artículo 37 de la Ley de la Ciencia] (así como otros que pudieran derivarse de la obtención de financiación europea, autonómica o local), desde la Universidad se va a proceder a la extracción de las referencias de vuestras publicaciones desde el Curriculum Vitae del Investigador en el Campus Virtual y su inclusión en el Repositorio Institucional de la UA (RUA). También se procederá a la carga en RUA de los artículos de investigación publicados, siempre que sea posible su localización y, cuando la política de la editorial lo permita, se ofrecerá acceso abierto a éstos. El personal de RUA verificará la política editorial de cada una de las revistas donde se hayan publicado los artículos, a fin de cumplir los requisitos planteados por las distintas editoriales. Desde la Biblioteca Universitaria podrán dirigirse a los autores de los artículos para la obtención de una copia de las publicaciones, cuando no sea posible su localización por otros medios."

Este apoyo institucional consiguió convertir al repositorio institucional en depositario de los artículos científicos revisados por pares publicados por los investigadores de la universidad, permitiendo a la Biblioteca Universitaria actuar "de oficio" en la búsqueda, localización, depósito, preservación y difusión de dichos artículos, consiguiendo el archivo de casi el $100 \%$ de los artículos publicados en revistas científicas, con un porcentaje de en torno al $70 \%$ de acceso abierto a los trabajos depositados. Y, quizás lo más relevante, sin ningún tipo de reticencia o rechazo por parte del personal investigador, que ha visto al repositorio como una herramienta al servicio de la institución y de sus integrantes, y a la Biblioteca como apoyo para conseguir una mayor difusión de sus publicaciones, sin necesidad de emplear parte de su tiempo en esta tarea.

Por último, para responder a la pregunta planteada en el título de esta aportación, y circunscribiendo el análisis a nuestra experiencia, la respuesta es que los repositorios no deben ser competidores de las redes sociales académicas. Es aconsejable observar sus desarrollos tecnológicos y los servicios de valor añadido que aportan a los investigadores e intentar, en la medida de lo posible, adaptar los avances a nuestras necesidades para ofrecer más y mejores servicios, pero esto no implica que los repositorios y las redes sociales académicas no puedan coexistir, cada uno con sus propios objetivos y prioridades. 